\title{
Exploring youth civic engagement: a view from England
}

Book or Report Section

Supplemental Material

Harris, R. (2017) Exploring youth civic engagement: a view from England. In: Broom, C. (ed.) Youth Civic Engagement in a Globalized World : Citizenship Education in Comparative Perspective. Palgrave studies in global citizenship education and democracy. Palgrave Macmillan, New York, pp. 37-58. ISBN 9781137565327 doi: https://doi.org/10.1057/978-1-13756533-4 Available at http://centaur.reading.ac.uk/66277/

It is advisable to refer to the publisher's version if you intend to cite from the work. See Guidance on citing.

To link to this article DOI: http://dx.doi.org/10.1057/978-1-137-56533-4

Publisher: Palgrave Macmillan

All outputs in CentAUR are protected by Intellectual Property Rights law, including copyright law. Copyright and IPR is retained by the creators or other copyright holders. Terms and conditions for use of this material are defined in the End User Agreement. 


\section{www.reading.ac.uk/centaur}

\section{CentAUR}

Central Archive at the University of Reading

Reading's research outputs online 
Table 1 - summary of participants' survey responses

\begin{tabular}{|c|c|c|c|c|c|c|}
\hline \multicolumn{7}{|c|}{ Demographics of British youth in the survey } \\
\hline Gender & \multicolumn{2}{|c|}{$\begin{array}{l}\text { Female: } 69 \%^{1} \\
(104)\end{array}$} & \multicolumn{2}{|c|}{ Male: $29 \%(44)$} & \multicolumn{2}{|c|}{ Other: $1 \%(2)$} \\
\hline Age profile & \multicolumn{2}{|c|}{ 16: $46 \%(31)$} & \multicolumn{2}{|c|}{$17: 50 \%(75)$} & \multicolumn{2}{|c|}{ 18: $19 \%(29)$} \\
\hline Socio-economic status & \multicolumn{2}{|c|}{ 'high': 4\% (6) } & \multicolumn{2}{|c|}{$\begin{array}{l}\text { 'middle': } 77 \% \\
(115)\end{array}$} & \multicolumn{2}{|c|}{ 'low': 16\% (24) } \\
\hline Cultural identification & \multicolumn{2}{|c|}{$\begin{array}{l}\text { British: } 67 \% \\
\text { (101) }\end{array}$} & \multicolumn{2}{|c|}{ Other: $27 \%(40)$} & \multicolumn{2}{|c|}{ Undisclosed: 6\% (9) } \\
\hline First language & \multicolumn{2}{|c|}{$\begin{array}{l}\text { English: } 137 \\
(91 \%)\end{array}$} & \multicolumn{4}{|c|}{ Other: $13(9 \%)$} \\
\hline Personality type $^{2}$ & $\begin{array}{l}\text { Leader: } \\
47 \%(37)\end{array}$ & $\mathrm{Fr}$ & lly: 11\% & $\begin{array}{l}\text { Outgo } \\
22 \%\end{array}$ & & $\begin{array}{l}\text { Introverted: } \\
31 \%(47)\end{array}$ \\
\hline \multicolumn{7}{|l|}{ Survey responses } \\
\hline & \multicolumn{2}{|l|}{ Yes } & \multicolumn{2}{|l|}{ No } & \multicolumn{2}{|c|}{ Unsure } \\
\hline $\begin{array}{l}\text { Citizenship education about } \\
\text { govt. }\end{array}$ & \multicolumn{2}{|l|}{$39 \%(59)$} & \multicolumn{2}{|c|}{$53 \%(79)$} & \multicolumn{2}{|c|}{$8 \%(12)$} \\
\hline
\end{tabular}

\footnotetext{
${ }^{1}$ All percentages are valid percentages, i.e. reflects the number of actual responses to each question, and are rounded to the nearest whole number

2 Personality types were described as leader/driven to succeed/competitive; friendly/relaxed/optimistic; likes working with others/outgoing; and likes working with others/organised/introverted. For ease of use they will be referred to as 'leader', 'friendly', 'outgoing' and 'introverted'
} 


\begin{tabular}{|c|c|c|c|}
\hline & Knowledgeable & $\begin{array}{l}\text { Some } \\
\text { knowledge }\end{array}$ & Lack knowledge \\
\hline \multirow[t]{2}{*}{$\begin{array}{l}\text { Knowledge of govt. and } \\
\text { politics }\end{array}$} & $23 \%(32)$ & $63 \%(88)$ & $14 \%(9)$ \\
\hline & Yes & Sometimes & No \\
\hline \multirow[t]{2}{*}{ Follow the news } & $61 \%(91)$ & $37 \%(55)$ & $3 \%(4)$ \\
\hline & Yes & No & Unsure \\
\hline Personal experience & $22 \%(32)$ & $73 \%(109)$ & $5 \%(8)$ \\
\hline \multirow[t]{2}{*}{ Family interest } & $17 \%(25)$ & $71 \%(107)$ & $5 \%(8)$ \\
\hline & Important & Quite important & Not important \\
\hline \multirow[t]{2}{*}{ Civic engagement } & $47 \%(71)$ & $47 \%(70)$ & $4 \%(6)$ \\
\hline & Active & $\begin{array}{l}\text { Occasionally } \\
\text { active }\end{array}$ & Not active \\
\hline \multirow[t]{2}{*}{$\begin{array}{l}\text { Level of personal } \\
\text { engagement }\end{array}$} & $21 \%(32)$ & $47 \%(71)$ & $27 \%(40)$ \\
\hline & Effective & $\begin{array}{l}\text { Somewhat } \\
\text { effective }\end{array}$ & Ineffective \\
\hline Ability to influence change & $25 \%(35)$ & $45 \%(63)$ & $31 \%(43)$ \\
\hline
\end{tabular}




\begin{tabular}{|c|c|c|c|}
\hline & Supportive & Neutral & $\begin{array}{l}\text { Do not care/not } \\
\text { supportive }\end{array}$ \\
\hline $\begin{array}{l}\text { Attitudes towards } \\
\text { democracy }\end{array}$ & $65 \%(88)$ & $22 \%(30)$ & $13 \%(17)$ \\
\hline $\begin{array}{l}\text { Attitude towards govt. } \\
\text { system in UK }\end{array}$ & $39 \%(55)$ & $46 \%(65)$ & $14 \%(20)$ \\
\hline & Important & Neutral & Not important \\
\hline Political engagement & $54 \%(75)$ & $39 \%(55)$ & $7 \%(10)$ \\
\hline $\begin{array}{l}\text { Students' civic participation } \\
\text { (top 3) (NB voting was } 9^{\text {th }} \text { on } \\
\text { the list however few of the } \\
\text { students surveyed were of } \\
\text { voting age) }\end{array}$ & Yes & No & No response \\
\hline Donating money to causes & $64 \%(96)$ & $33 \%(50)$ & $3 \%(4)$ \\
\hline Volunteering & $61 \%(91)$ & $37 \%(55)$ & $3 \%(4)$ \\
\hline Being a good neighbour & $51 \%(77)$ & $46 \%(69)$ & $3 \%(4)$ \\
\hline
\end{tabular}

